\title{
The Use of Symmetrical Angle Switched Single- \& 3-Phase Rectifiers in Micro Hydro Power Plants
}

\author{
Henry Bory-Prevez ${ }^{(1)}$; Herminio Martínez-García ${ }^{(2)}$, Member, IEEE; Luís Vázquez-Seisdedos ${ }^{(1)}$; \\ Encarna García-Vílchez ${ }^{(2)}$; and Antoni Grau-Saldes ${ }^{(3)}$, Member, IEEE
}

\author{
(1) Automatic Control Dept. \\ Electrical Engineering Faculty \\ University of Oriente \\ Santiago de Cuba, Cuba \\ \{bory; 1vazquez\}@uo.edu.cu
}

\author{
(2) Electronics Engineering Department \\ Eastern Barcelona School of Engineering (EEBE) \\ Tech. University of Catalonia (UPC), BarcelonaTech \\ Barcelona, Spain \\ \{herminio.martinez; encarna.garcia.vilchez\}@upc.edu
}

\author{
(3) Automatic Control Dept. \\ Tech. University of Catalonia (UPC), \\ BarcelonaTech \\ Barcelona, Spain \\ antoni.grau@upc.edu
}

\begin{abstract}
Micro-size hydro power plants ( $\mu$ HPPs) are commonly used at remote areas to supply islanded AC microgrids. A typical way to control grid frequency is to manipulate active power dissipated in ballast loads by $\mathrm{AC} / \mathrm{AC}$ converters. However, these asymmetrically switched thyristor controlled converters consume reactive power degrading the power factor at the generator output. In this paper the operation of a symmetric angle switched, bridged three-phase rectifier and three single-phase rectifiers connected in series with ballast load, are studied to improve the power factor of the system. As a consequence, the objective is to evaluated the use of the three and single-phase rectifiers switched with symmetrical angle to improve the power factor, by reactive power compensation, at the output terminal of the electric generator of $\mu \mathrm{HPPs}$ that use ballast load to regulate frequency.
\end{abstract}

Keywords-Controlled rectifiers, switching AC/AC converters, power factor, symmetrical switching.

\section{INTRODUCTION}

Due to climate issues and exhaustible resources of fossil energy, more and more attention has been paid to the utilization of renewable energy sources [1]-[4]. Distributed renewable generation based micro grids operated in island mode has become more popular to build energy self-sufficient areas, e.g. electrification of rural areas apart from national grids [5], [6].

In Cuba, micro hydro power plants ( $\mu \mathrm{HPPs}$ ) supplied micro grids are utilized in the electrification of off-grid rural areas. At this moment there are $117 \mu \mathrm{HPPs}$ placed mainly in provinces of the Orient region operating in island mode isolated from the National Electrical System. $\mu$ HPPs do not require big volumetric water flows, and they produce less harmful environmental impacts compared e.g. diesel generators [7].

Frequency regulation in $\mu \mathrm{HPP}$ supplied islanded micro grids is typically done by manipulating the dissipated power in ballast loads controlled by AC/AC converters shunted with grid loads. The active power supplied by the generator $\left(P_{G}\right)$ must equal with the dissipated power by the ballast load $\left(P_{L}\right)$ plus the active power consumed by the users $\left(P_{U}\right)$. Thus, according to Fig. 1, the basic equation describing this type of regulation is: $P_{G}=P_{L}+P_{U}$.

Reference [8] has shown that $\mathrm{AC} / \mathrm{AC}$ converters consume reactive power degrading the power factor at the generator output terminals. The objective of this paper is to evaluate the use of three-phase and single-phase symmetrical angle switched rectifiers to improve the power factor by reactive power compensation at the output terminal of the generator in the frequency control of $\mu$ HPP supplied micro grids.
The evaluated system parameters are the effective current, the active, reactive, and apparent powers, distortion power and the power factor.

The structure of this paper is as follows: Section 2 and 3 present briefly operation principles of three-phase and singlephase rectifiers switched with symmetrical angle. Section 4 presents the $\mu \mathrm{HPP}$ model built with Psim ${ }^{\circledR}$ modelling tool, and the equations for reactive power to demonstrate reactive power consumption of an AC/AC converter. Finally, Section 5 introduces the application of the symmetrical angle switched rectifiers, and makes a comparison with respect to the power factor at the output terminals of the generator.

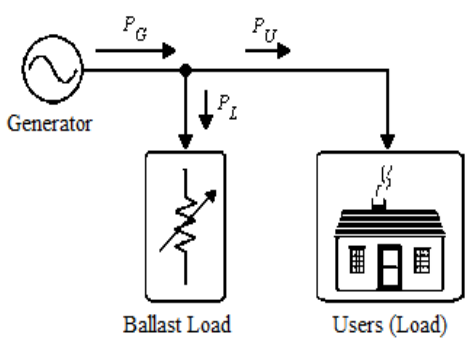

Fig. 1. General scheme of the frequency regulation of a microgrid by the ballast load.

\section{THREE-Phase BRIDGE WITH A SWITCH IN SERIES WITH THE BALLAST LOAD}

This section introduces the simulation scheme of the threephase rectifier shown in Fig. 2 and the mathematical expressions of the evaluated system parameters [9].

The simulation model consists of the following elements: Three-phase sinusoidal voltage source as a generator, (VSIN3), with frequency of $60 \mathrm{~Hz}$ and phase to phase effective voltage $190.53 \mathrm{~V}$; a 3-phase diode bridge rectifier (BD3); an isolated gate bipolar transistor (IGBT) switch (IS); and the gating system $(G 1)$ producing the desired gating sequence to the switch. Parameters of the gating function are frequency $(360 \mathrm{~Hz})$, number of switching points (2), and switching point parameters (triggering angles and pulse width). The ballast load resistance is $R=4.03 \Omega$, and the measured voltages and currents are $V_{a}, V_{b}, V_{c}, V_{R}, I_{L a}, I_{L b}$ and $I_{L c}$. The measurements show the instantaneous wave forms of the voltage in each phase, the voltage across the ballast load $R$, and the phase currents in the rectifier input terminal.

Fig. 3 shows the waveforms of voltages and currents of the rectifier circuit with a switching angle $\alpha$ of $15^{\circ}$. The voltagecurrent phase angle $\varphi_{1}$ is zero for all switching angles. Thus, there are no phase shifts between the phase voltages and the 
first harmonics of the instantaneous currents in the input terminals of the rectifier.

The effective current at the rectifier input is:

$$
I_{r m s}=\frac{\sqrt{2} \sqrt{3} V_{e f}}{R} \sqrt{\frac{1}{\pi}\left[\frac{\pi}{3}-2 \alpha+\frac{\sqrt{3}}{2} \cos (2 \alpha)-\frac{\sin (2 \alpha)}{2}\right]}
$$

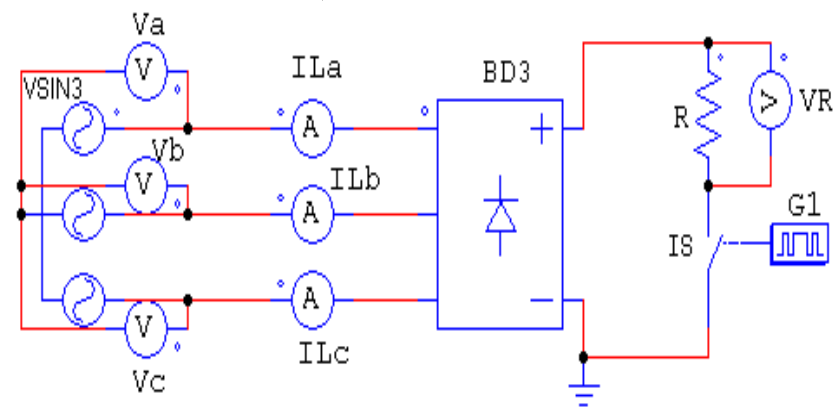

Fig. 2. Simulation model of the three-phase rectifier and the switchcontrolled ballast load implemented in PSIM ${ }^{\circledR}$.

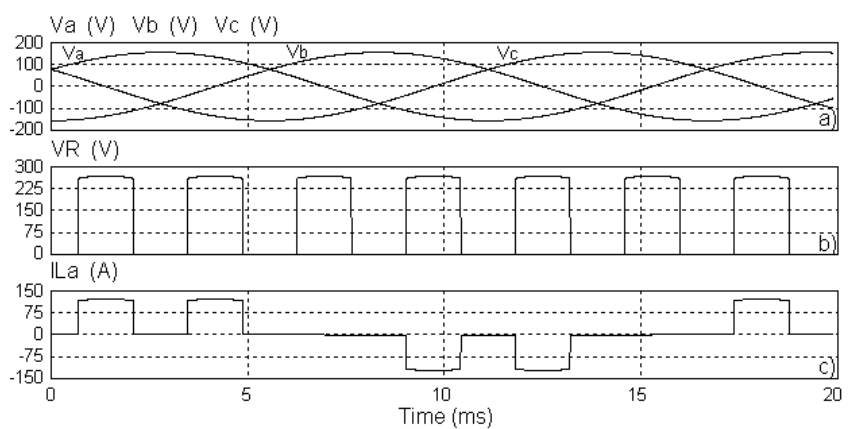

Fig. 3. The waveforms of the three-phase rectifier switched with symmetrical angle: (a) Phase voltages at the generator output terminals, $(b)$ voltage across $R$, and $(c)$ phase current $I L_{a}$ at the rectifier input terminal.

The active $(P)$, reactive $(Q)$, and apparent $(S)$ powers and distortion power $(T)$ at the rectifier input terminal are given, respectively, by means of (2), (3), (4), and (5).

$$
P_{3 e n t}=\frac{9 V_{e f}^{2}}{\pi R}\left[\frac{\pi}{3}-2 \alpha+\frac{\sqrt{3}}{2} \cos (2 \alpha)-\frac{\sin (2 \alpha)}{2}\right],
$$

where the maximum active power output is achieved with switching angle $\alpha=0$.

$$
Q_{3 e n t}=0
$$

The result is evident for the zero voltage-current phase angle $\varphi_{1}$, and it shows that the rectifier switched with symmetrical angle has no consumption of reactive power with any switching angle value.

$$
S_{3 e n t}=\frac{3 \sqrt{6} V_{e f}^{2}}{R} \sqrt{\frac{1}{\pi}\left[\frac{\pi}{3}-2 \alpha+\frac{\sqrt{3}}{2} \cos (2 \alpha)-\frac{\sin (2 \alpha)}{2}\right]}
$$

The maximum apparent power output is achieved with switching angle $\alpha=0$. The distortion power is given by:

$$
T_{3 e n t}=\frac{9 V_{e f}^{2}}{\pi R} \sqrt{\frac{\pi^{2}}{9}-\left[2 \alpha-\frac{\sqrt{3}}{2} \cos (2 \alpha)+\frac{\sin (2 \alpha)}{2}\right]^{2}}
$$

For $\alpha=0, T_{3 \text { ent }}=0.308 P_{3 \text { entmax }}$. This is different from zero, because the values of the currents at the rectifier input terminals are not sinusoidal. For $\alpha=\pi / 6, T_{3 \text { ent }}=0$, because the current at the rectifier input terminals is zero.
The power factor of the rectifier is:

$$
f p=\sqrt{\frac{3}{2 \pi}\left[\frac{\pi}{3}-2 \alpha+\frac{\sqrt{3}}{2} \cos (2 \alpha)-\frac{\sin (2 \alpha)}{2}\right]}
$$

Note, for $\alpha=0$, the power factor $f p=0.956$. As previously mentioned, for this angle the currents at the rectifier input terminals are not sinusoidal.

\section{SingLe-Phase Type BRIDGE RECTIFIER WITH A SWITCH IN SERIES WITH THE BALLAST LOAD}

In this section, the simulation scheme of the single-phase rectifier with the symmetrically switch-controlled ballast load (Fig. 4), and the mathematical expressions of the system variables are presented [9].

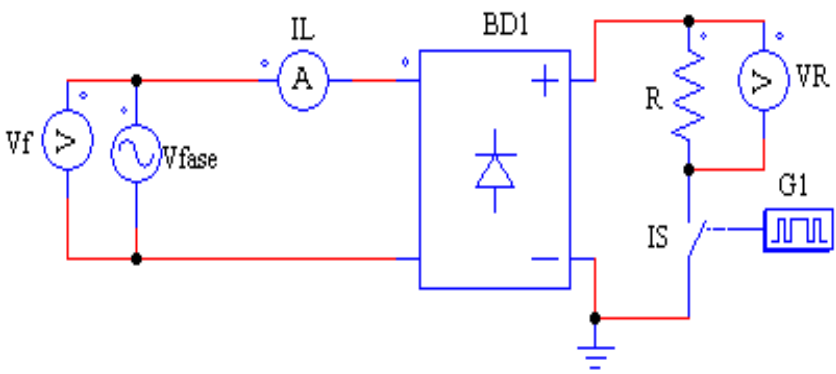

Fig. 4. Simulation model of the single-phase rectifier and a switchcontrolled ballast load implemented in PSIM ${ }^{\circledR}$.

The simulation model consists of the following elements: single phase sinusoidal voltage source (Vfase) with frequency $60 \mathrm{~Hz}$ and effective voltage $110 \mathrm{~V}$; single phase diode bridge rectifier $(B D 1)$; IGBT switch $(I S)$; and the gating system $(G 1)$ producing the desired gating sequence to the switch. Parameters of the gating function are frequency $(120 \mathrm{~Hz})$, number of switching points (2), and triggering angles and pulse widths of gating pulses. The ballast load resistance $R$ is $4.03 \Omega$, and the voltage and current measurements $\left(V_{f}, V_{R}, I_{L}\right)$ show the instantaneous wave forms of the source voltage, the voltage across $R$ and the current $I_{L}$ at the rectifier input. Fig. 5 shows waveforms of the voltage and the current for the rectifier circuit with a switching angle of $30^{\circ}$. The voltagecurrent phase angle, $\varphi_{1}$, is zero for all switching angle values, thus there is no phase shift between the phase voltage and the first harmonic of the instantaneous current to the rectifier input. Moreover, the effective current at the rectifier input is:

$$
I_{r m s}=\frac{V_{e f}}{R} \sqrt{\frac{\pi-2 \alpha+\sin (2 \alpha)}{\pi}}
$$

In this second case, the active $(P)$, reactive $(Q)$, and apparent $(S)$ powers, and the distortion power $(T)$ at the rectifier input terminal are given, respectively, by (8), (9), (10), and (11).

$$
P_{e n t B D}=\frac{V_{e f}^{2}}{\pi R}[\pi-2 \alpha+\sin (2 \alpha)]
$$

The maximum active power output is achieved with switching angle $\alpha=0$.

$$
Q_{\text {ent }}=0
$$

Again, this result is obtained from the mathematical expression of the voltage-current phase angle, and it informs that the rectifier switched with symmetrical angles does not 
consume reactive power at any switching angle value. The apparent power is given by (10).

$$
S_{\text {entBD }}=\frac{V_{e f}^{2}}{R} \sqrt{\frac{\pi-2 \alpha+\sin (2 \alpha)}{\pi}}
$$

The maximum apparent power $S_{\text {entBDmáx }}=V_{e f}^{2} / R$ is achieved with $\alpha=0$, and it equals with the maximum active power dissipated in the load resistance. Distortion power is

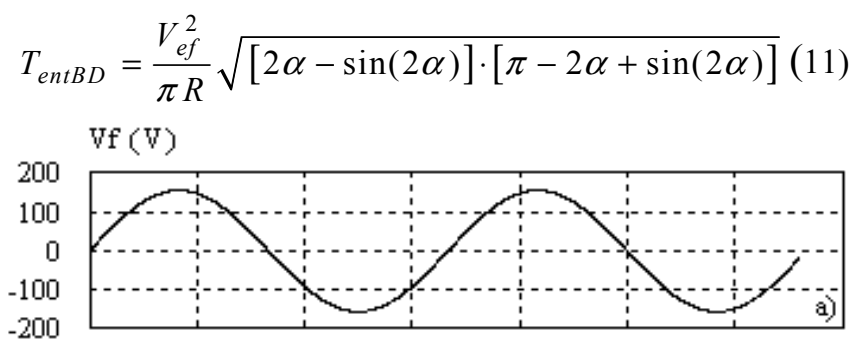

$\mathrm{WF}(\mathrm{V})$

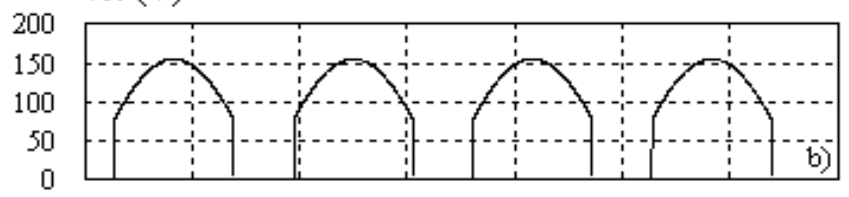

IL. $(A)$

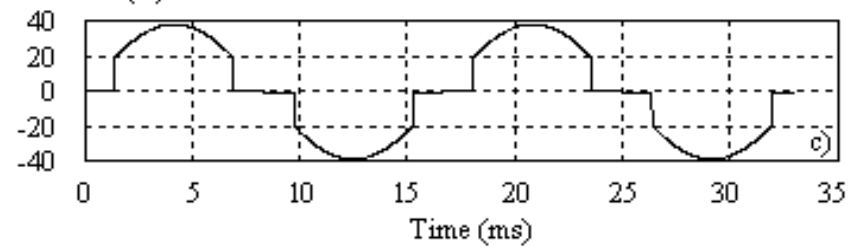

Fig. 5. Waveforms of the single-phase rectifier switched with symmetrical angle: $(a)$ Source voltage, $(b)$ voltage across $R$, and $(c)$ current at the rectifier input terminal.

For $\alpha=0, T_{\text {entBD }}=0$. This is because with $\alpha=0$, the current at the rectifier input terminal is sinusoidal. For $\alpha=\pi / 2$, $T_{\text {entBD }}=0$, because the current at the rectifier input terminal is zero. The power factor to the input of the rectifier is:

$$
f p=\sqrt{\frac{\pi-2 \alpha+\sin (2 \alpha)}{\pi}}
$$

Note, for $\alpha=0$, the power factor $f p=1$. This is because the current at the rectifier input terminal is sinusoidal and there is no phase-shift between voltage and current.

\section{PSIM ${ }^{\circledR}$ MODEL FOR THE MicRo HYDROPOWER PLANT SCHEME}

This section presents the PSIM $^{\circledR}$ model representing the $\mu \mathrm{HPP}$ electric scheme. AC/AC converter is applied to regulate the power dissipated by the ballast load and to control the micro grid's system frequency. It is also shown that the $\mathrm{AC} / \mathrm{AC}$ converter consumes inductive reactive power.

The system model presented in Fig. 6 consists of following components: sinusoidal voltage source VSIN3 (three-phase generator); grid load, RLusers; three AC/AC converters with gating units $\boldsymbol{G 1}$ to $\mathbf{G 6}$; ballast loads Rballast 1, Rballast 2 and Rballast 3; alternating current meters (ILa, ILb, ILc, ILua, $I L u b, I L u c, I a B D, I b B D$, e IcBD), Watt-meters, Var-meters, $\mathrm{VA}$ and power factor meters $(\boldsymbol{W} 3 L, V A R 3 L, V A P F 3 L, W 3 u$, $V A R 3 u, V A P F 3 u, W 3 B D, V A R 3 B D$, and $V A P F 3 B D)$.
Reference [9] demonstrates that the $\mathrm{AC} / \mathrm{AC}$ converter has the disadvantage of consumption of inductive reactive power degrading the power factor at the generator output terminals. $\mathrm{AC} / \mathrm{AC}$ converter's reactive power is:

$$
Q_{\text {ent } A C / A C}=\frac{V_{e f}^{2}}{\pi R}\left[\frac{1-\cos (2 \alpha)}{2}\right]
$$

Fig. 7 shows the curve of the reactive power divided by the maximum active power as function of the triggering angle $(\alpha)$. The reactive power has its maximum value at $\alpha=\pi / 2 \mathrm{rad}$ and it is 0.318 times the maximum active power. Notice that $P_{\alpha 0}$ is the maximum active power at the AC/AC converter input, and it is obtained from (14) with $\alpha=0$.

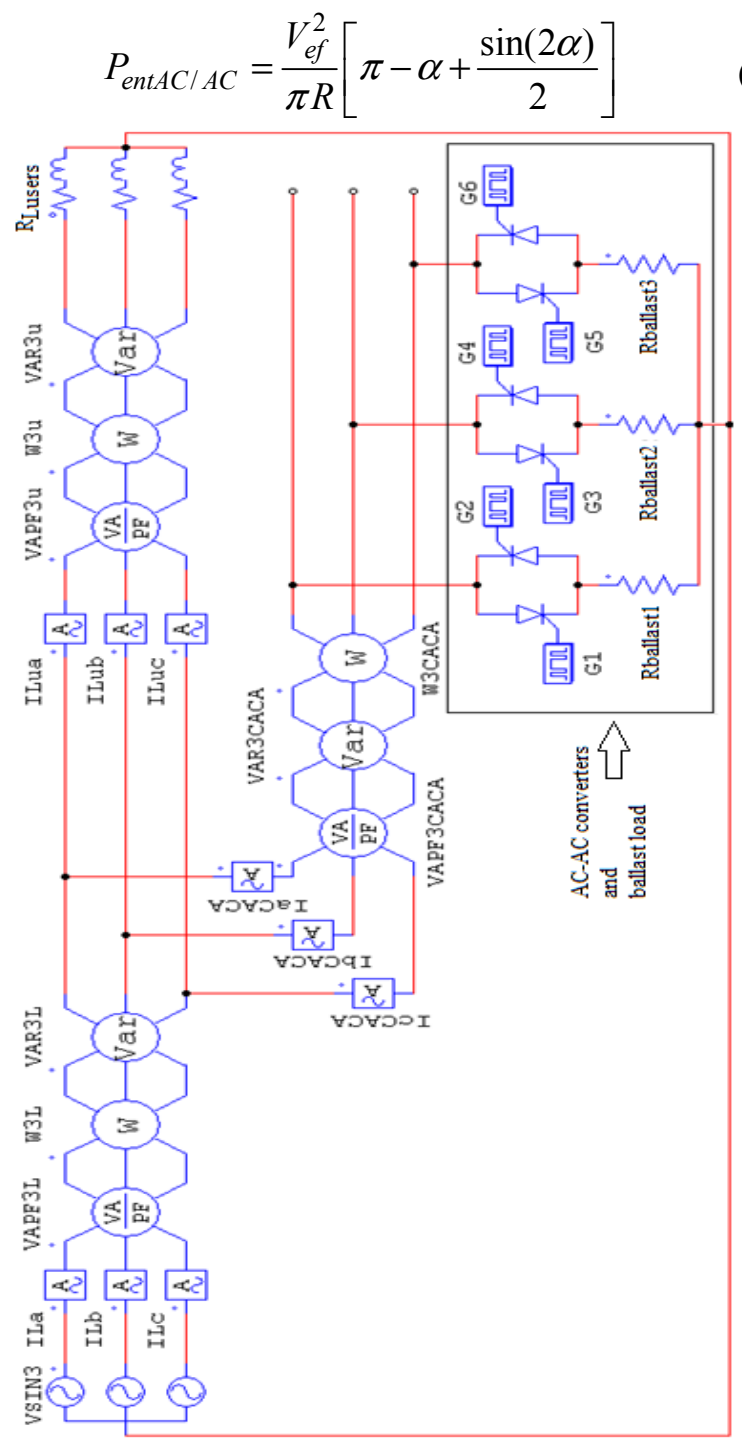

Fig. 6. PSIM ${ }^{\circledR}$-based simulation model of the $\mu \mathrm{HPP}$ generationconsumption system with three AC/AC converters controlling ballast loads.

\section{COMPARISON REsults OF THE SingLE AND THREE-PHASE RECTIFIERS APPLIED TO MICRO HYDROPOWER PLANTS}

In section symmetrically switched three-phase and singlephase rectifiers are compared with Figure 6 type conventional $\mu \mathrm{HPP}$ scheme. The results show the power factor improvements at the electrical generator output terminals for load control schemes accomplished with symmetrical switched rectifiers compared with conventional AC/AC converter. For the comparison, the active power and effective 
current from the $\mu$ HPP have been measured. The minimum and maximum analyzed active power loads are $P_{u m i n}=3 \mathrm{~kW}$ and $P_{\text {umáx }}=12 \mathrm{~kW}$. The load has an inductive power factor equal to 0.7 .

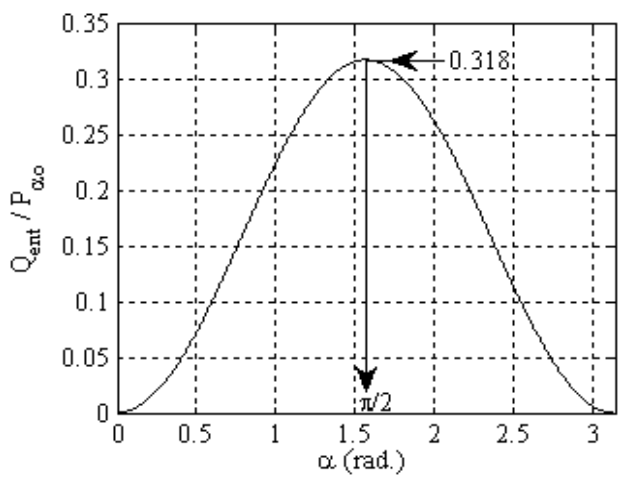

Fig. 7. $Q_{\text {ent }} / P_{\alpha 0}$ as a function of the triggering angle $\alpha$.

The following schemes have been simulated: a) Fig. 6 types conventional $\mathrm{AC} / \mathrm{AC}$ converter with non-symmetric switching; $b$ ) replacing the conventionally controlled AC/AC converters with the three-phase rectifier switched with symmetrical angle.

Fig. 8 represents the power factor at the generator output for the symmetrically switched three-phase rectifier, $f p_{G S} B D 3$, and for the conventionally controlled $\mathrm{AC} / \mathrm{AC}$ converters, $f p_{G S} A C A C$. It is shown that the power factor for symmetrically switched three-phase converter, $f p_{G S} B D 3$, is bigger than $f p_{G S} A C A C$ only at the $94.5 \%$ of the active power range $P_{U}$. Near to $P_{u m i n}, f p_{G S} B D 3$ is smaller than $f p_{G S} A C A C, 0.02$ as maximum. That is because for the symmetrically switched rectifier the distortion power is greater than distortion and the inductive reactive powers consumed by the three $\mathrm{AC} / \mathrm{AC}$ converters. The maximum difference of $f p_{G S} B D 3$ and $f p_{G S} A C A C$ is equal to 0.06 , and $f p_{G S} B D 3$ and $f p_{G S} A C A C$ have the same value, 0.94 , at $P_{U}=3.5 \mathrm{~kW}$.

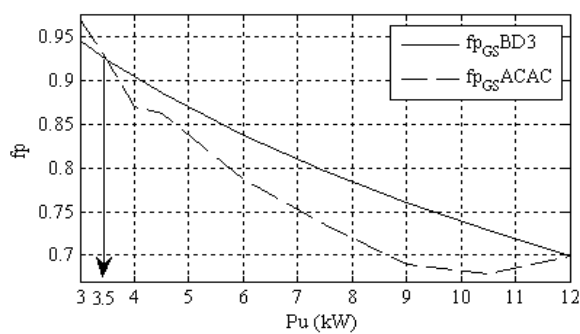

Fig. 8. Comparison between the power factors at the generator output for the three-phase rectifier, $f p_{G S} B D 3$, and the conventional AC/AC converters, $f p_{G S} A C A C$.

The result indicates that it is possible to utilize the threephase rectifier switched with symmetrical angle to improve the power factor at the generator output.

In the next case the objective is to study, if it is possible to improve the power factor with symmetrical angle switched single phase rectifiers through the entire controllable power range. The conventional $\mathrm{AC} / \mathrm{AC}$ converter scheme is comparedwith the three symmetrical-angle switched singlephase AC/AC converters. Fig. 9 is represents the power factor at the generator output when the grid frequency is controlled by the three single phase rectifiers, $f p_{G S} B D$, and by the conventional $\mathrm{AC} / \mathrm{AC}$ converters, $f p_{G S} A C A C$. The figure shows that $f p_{G S} B D$ is bigger or equal than $f p_{G S} A C A C$ over the whole active power range $P_{U}$. In addition, at $P_{u, \text { min }}$, we have $f p_{G S} B D=f p_{G S} A C A C=0.97 ; \quad$ and at $P_{u, \max }$, $f p_{G S} B D=f p_{G S} A C A C=0.699$. In any case, the maximum difference between $f p_{G S} B D$ and $f p_{G S} A C A C$ is equal to 0.075 .

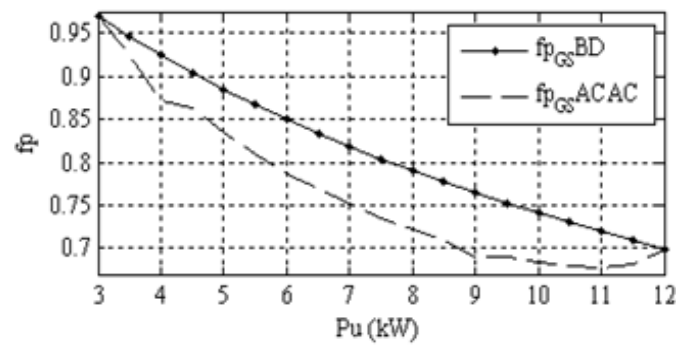

Fig. 9. Comparison between the power factors at the generator output when the system is controlled by three single phase rectifiers, $f p_{G S} B D$, and by the conventional AC/AC converters, $f p_{G S} A C A C$.

The simulation results show that in ballast load control the power factor at the generator output can be improved by substituting each AC/AC converter with a single phase rectifier switched with symmetrical angle.

\section{ACKNOWLEDGMENT}

This work has been partially supported by the Spanish Ministerio de Ciencia, Innovación y Universidades (MICINN)-Agencia Estatal de Investigación (AEI) and the European Regional Development Funds (FEDER), by project PGC2018-098946-B-I00.

\section{REFERENCES}

[1] D. Wu et al., "Autonomous Active Power Control for Islanded AC Microgrids with Photovoltaic Generation and Energy Storage System," IEEE Transactions on Energy Conversion 4, 2014, pp. 882-892.

[2] M. Castro et al., "Integration of Renewable Energy Source in the Cuban Electric Power System," Project PR-759, Project Register System, Cujae, 2016, available at: http://www.cujae.edu.cu/investigaciones/sistema de registro de proyectos

[3] M. Castro et al., "Integration of Renewable Energy Sources in Cuba,", Memories of Seminar Energy Future of Energy in Cuba, International Fair on Renewable Energy, Pabexpo, Havana, Cuba, 2018.

[4] O. Hohmeyer, J. Welle "Cuban Society Based on $100 \%$ Renewable Energy Sources: A First Scenario Analysis," CRECEco-funded by the Erasmus + Programme of the European Union, Kick-Off January Weeks in Technological University of Havana and University of Oriente, Cuba, 2018.

[5] A. Naqui, A. Ahmad, "A lossless switching technique for smart grid applications," Int J. Electr Power Energy Syst 49, 2013, pp. 213-220.

[6] I. Colak, E. Kabalci, G. Fulli, S. Lazarou, "A Survey on the Contributions of Power Electronics to Smart Grid Systems". Renewable Sustainable Energy 47, 2015, pp. 562-579. doi:10.1016/j.rser.2015.03.031

[7] J. Fong et al., "Design of a Regulator of Frequency, for Small Central Hydroelectric in Isolated Operation", Journal of Engineering and Technology for Industrial Applications, 2018, DOI: https://dx.doi.org/10.5935/2447-0228.20180021.

[8] V. Kurtz, F. Botteró, "Una Alternativa para el control de Cargas Balasto que Regulan Frecuencia y Tensión en PCH de Operación Aislada," Available online: http://www.cerpch.unifei.edu.br/arquivos/artigos/44c1e4324ee3998d0 1c61875a2288b61.pdf. Consulted: [19-05-2014].

[9] H. Bory, H. Martínez-García, L. Vázquez, “Comparación entre Rectificador Monofásico con Conmutación Simétrica y Convertidor AC/AC para la Mejora del Factor de Potencia en Microcentrales Hidroeléctricas," Revista Iberoamericana de Automática e Informática industrial, vol. 16 ( $\mathrm{n}^{\circ}$ 1), 2019, https://doi.org/10.4995/riai.2018.9313

[10] IPCC (2011) Special Report on Renewable Energy Sourcesand Climate Change Mitigation. Cambridge University Press,Cambridge, United Kingdom and New York, NY, USA. 